\title{
La garantía de arrendamiento en materia de inquilinato, falta de normativa y seguridad jurídica
}

\author{
The lease guarantee in terms of tenancy, lack of regulations and legal certainty \\ A garantia do arrendamento em termos de arrendamento, falta de \\ regulamentação e segurança jurídica
}

\author{
Laura Consuelo Baque Andrade \\ abglaurabaque@gmail.com \\ Abigail Sequeiros Olivares \\ abigailcide@gmail.com \\ laurabaqueandrade@outlook.com \\ ORCID: 0000-0003-3426-6811 \\ Universidad Central del Ecuador
}

Universidad Central del Ecuador

Artículo recibido en enero 2019 / Arbitrado en marzo 2019 / Publicado en abril 2019

RESUMEN

ABSTRACT

RESUMO

Esta investigación conlleva a un análisis socio-económico crítico respecto de la afectación del ejercicio de los derechos de los inquilinos y arrendadores, principalmente la falta de normativa de la garantía en materia de inquilinato que constituye un problema común. La investigación tuvo como objetivo principal la elaboración de políticas públicas con el fin de proteger el derecho a la vivienda y la seguridad jurídica. De esta manera, la investigación se basa en una investigación descriptiva- no experimental, de campo, modalidad proyecto factible. Se usaron los métodos inductivos, deductivos, histórico-lógico, entre otros. Por el cual se utilizaron como técnica, la observación, encuesta , entrevista, el instrumento para la recolección de datos fue el cuestionario, la población y muestra estuvo conformada por 155 personas del Distrito Metropolitano de Quito. De esta manera, se evidencio que la población desconoce la garantía por arrendamiento y el valor que deben cancelar al momento de arrendar un inmueble.

Palabras clave: Garantía de arrendamiento; contrato de arrendamiento; arrendador y arrendatario; seguridad jurídica, políticas públicas

This research leads to a critical socio-economic analysis regarding the impact on the exercise of the rights of tenants and landlords, mainly the lack of guarantee regulations regarding tenancy, which is a common problem. The main objective of the research was to develop public policies in order to protect the right to housing and legal security. In this way, the research is based on a descriptive research - not experimental, field, feasible project modality. Inductive, deductive, historical-logical methods, among others, were used. For which observation, survey, interview, the instrument for data collection was the questionnaire, the population and sample were made up of 155 people from the Metropolitan District of Quito. In this way, it was evidenced that the population is unaware of the lease guarantee and the value that they must cancel at the time of leasing a property.

Key words: Lease guarantee; leasing contract; landlord and tenant; legal security, public policies

Esta pesquisa leva a uma análise socioeconômica crítica sobre o efeito dos inquilinos e dos serviços aos inquilinos, principalmente devido à falta de regulamentação da posse, que é um problema comum. A pesquisa como principal objetivo no desenvolvimento de políticas públicas de proteção à vida e à segurança jurídica. Desta forma, a pesquisa é baseada na modalidade de projeto descritivo, experimental, pesquisa de campo e viabilidade. São utilizados métodos indutivos, dedutivos, histórico-lógicos, entre outros. Por isso o utilizaram como técnica, observação, levantamento, entrevista, o instrumento de coleta de dados foi o questionário, a população e a amostra foram compostas por 155 pessoas do Distrito Metropolitano de Quito. Desse modo, fica evidente que o assentamento não garante o aluguel e o valor que deve ser pago no momento do aluguel do imóvel.

Palavras chave: Garantia de arrendamento; contrato de arrendamento; senhorio e inquilino; segurança jurídica, políticas públicas 


\section{INTRODUCCIÓN}

Desde la antigüedad el hombre ha establecido como necesidad prioritaria la protección de su integridad personal, que se ha visto afectado de cierta manera por los agentes externos de la tierra, optando por refugios primitivos para su supervivencia, al pasar los años estos han ido evolucionando constantemente a través de la historia, en la actualidad a dicho refugios se denominan viviendas.

La vivienda constituye uno de los elementos primordiales para supervivencia del ser humano, actualmente para la convivencia familiar y social, en este contexto es fundamental identificar la vivienda como una necesidad básica del hombre, en tal razón esta investigación prioriza la vivienda como derecho inalienable del ser humano.

En el territorio ecuatoriano se ha estipulado dentro del marco normativo el reconocimiento del derecho a vivienda adecuada y digna con independencia de su situación económica. A su vez, en la carta magna establece que el estado garantizará el derecho a la vivienda, el derecho de uso y habitación para que los ciudadanos puedan alquilar un bien inmueble, además del derecho al patrimonio por parte del arrendador.

De esta manera, en la Constitución de la República del Ecuador del año 2008 se logró avanzar en los derechos y garantías, permitiendo mejorar la calidad de vida de los ciudadanos ecuatorianos y residentes, incorporando una nueva cosmovisión denomina "Buen Vivir", razón por la cual, este estudio toma como base la Carta Magna del Ecuador, dado a que es el principal instrumento que garantiza los derechos fundamentales.

Sin embargo, en la actualidad solo por costumbre, se ha determinado y establecido el monto que se debe pagar de garantía por concepto de alquiler de un inmueble destinado a la vivienda. En materia de inquilinato, este acto se hace por voluntad de las partes esto es arrendador, y arrendatario, mediante un acuerdo, sea verbal o escrito, (contrato de arrendamiento consensual) en el que intervienen a la aceptación y suscripción las dos partes.

No fue sino hasta el año 2013, cuando la asamblea nacional trató el proyecto de reformar la ley de inquilinato; uno de los principales temas a tratar acerca de la garantía de arrendamiento de inmuebles, ya que este malestar causó un daño inminente y generó insatisfacción en los ciudadanos. Esta propuesta de reforma una vez aprobada, en el segundo debate por la asamblea nacional, se remitió al ejecutivo el mismo, que por cuestiones políticas lo objetó en su totalidad, razón por la cual es necesario impulsar esta reforma desde una perspectiva social y no política que contribuya a garantizar los derechos individuales de las personas.

Por lo tanto, es primordial garantizar los derechos a la vivienda de la ciudadanía en general, principalmente del inquilino, ya que se genera una incertidumbre al no 
conocer los valores que se le debería cobrar por concepto de garantía, además se debe precautelar el patrimonio del arrendador estableciendo un justo precio que garantice el estado del inmueble que va hacer arrendado, contribuyendo de esta manera a la seguridad jurídica.

El estudio se llevó a cabo en el Distrito Metropolitano de San Francisco de Quito, dado a que, en los Juzgados de Inquilinato que han existido en esta Ciudad, y en la Unidad Judicial de lo Civil en la vigente en la actualidad, han existido varios procesos de controversia en materia de inquilinato, desde el año 2016 hasta el momento de la investigación. Esta figura de inquilinato, incide en los ciudadanos mediante la vulneración de sus derechos desde el momento preciso en que se da el alquiler de un bien inmueble destinado a la vivienda.

Mediante el diagnostico, se obtuvo que en la legislación de la República de Ecuador, no existe ningún estamento que trate sobre las garantías al momento de arrendar un inmueble, destinado a la vivienda, lo cual va acompañado de varios vacíos jurídicos que ha hecho que se recurra a la costumbre como fuente para regular estas relaciones, es decir, solo a través de un contrato de arrendamiento consensual entre el arrendado y arrendatario. Trayendo como consecuencia un alto nivel de desconocimiento en la ciudadanía en general, respecto del valor que debe pagar por concepto de garantía.

Esta ignorancia ciudadana que se produce en los inquilinos, genera gran preocupación en la sociedad ya que debe existir dentro de la Ley de Inquilinato de forma clara, precisa y detallada el valor, la forma y el lugar que se debe cancelar estos valores como garantía al arrendador.

En este contexto, el estudio determinó el monto de garantía de los bienes inmuebles destinados a la vivienda y permite, asegurar una convivencia social enmarcada en los principios básicos de la materia que regulan las relaciones.

Por esta razón, se establece de una manera prolija clara y concisa, el monto de los valores que debe consignar el inquilino al arrendador por el alquiler de un bien inmueble designado a la vivienda, para generar una cultura en materia de inquilinato. Por lo que el estudio tiene como propósito la elaboración de Política Pública para socializar la garantía de arrendamiento de los bienes inmuebles destinados a la vivienda, con el fin de proteger el derecho a la vivienda y la seguridad jurídica.

Con esta investigación se da una contribución en el ámbito social, jurídico y económico; en el primer punto porque la materia de inquilinato es eminentemente social e involucra sectores vulnerables de la sociedad y afecta derechos intrínsecos de las personas y derechos constitucionales de las personas como el derecho a la vivienda, en el segundo punto, jurídico porque el derecho regula las relaciones interpersonales y es menester que el estado norme estas relaciones, para coadyuvar a la seguridad social; y en el tercer y último punto, económico porque el factor dinero 
es el punto de controversia y es producto de esta investigación, la fijación, determinación informativa respecto del monto de garantía mejorará las relaciones entre arrendador y arrendatario.

\section{Marco histórico}

En Ecuador, la falta de normativa para la regulación de la garantía en los contratos de arrendamiento de bienes inmuebles destinados a la vivienda, vulnera el derecho a la vivienda del inquilino y la seguridad jurídica.

Para Santa María (1998) las garantías son los medios más comunes utilizados por la costumbre para verificar el cumplimiento de obligaciones de los inquilinos, donde el arrendatario en muchos de los casos es el más beneficiado, o a su vez puede ser repercutido por las pérdidas causadas en caso de que el arrendatario dañe o afecte la propiedad privada del mismo.

Por otro lado, la función económica establece el goce de una propiedad al momento de adquirir una obligación económica mediante un hecho contractual, mismo que está vinculado con lo jurídico por el hecho de la legalización de los contratos. (González, 2000)

\section{Garantía de arrendamiento}

La garantía: es una institución de Derecho Público de seguridad y de protección a favor del individuo, la sociedad o el Estado que dispone de medios que hacen efectivo el goce de los derechos subjetivos frente al peligro o riesgo de que sean desconocidos.

Está puede proteger al individuo de la potestad de castigo del Estado, o puede también proteger a la sociedad o al Estado de las actitudes del individuo que pudieran perturbar el régimen establecido. De ahí una garantía puede ser: una garantía individual, una garantía social y una garantía estatal.

\section{Garantía dentro de la legislación ecuatoriana}

Aunque la garantía de arrendamiento dentro de la legislación ecuatoriana no se encuentra normada, en el Código Civil Ecuatoriano en el libro IV título XXV, se encuentra el contrato de arrendamiento,

De esta manera, lo que se determinaría en el arrendamiento de bienes inmuebles destinados a la vivienda seria:

El arrendamiento urbano, donde el objeto del contrato es el goce y uso del inmueble ajeno, por un precio determinado y tiempo cierto. El inmueble debe ser determinado. La causa para cada parte es la prestación o promesa de una casa, departamento, cuarto, o cualquiera que sirviera para el uso de habitación y vivienda, 
por la otra parte, el arrendador percibir el canon y el arrendatario disfruta del inmueble.

\section{Garantía en los contratos de arrendamiento}

Durante el estudio, se percató que la mayoría de los contratos de arrendamiento, se han redactados "de buena fe", sin la asistencia de un profesional del derecho, y su celebración conjuntamente con las cláusulas establecidas en su mayoría son por costumbre. Mientras las partes cumplan con lo comprometido, en el contrato firmado "de buena fe" no hay problema alguno.

El inconveniente nace cuando esa buena fe, se ve vulnerada. Si el arrendatario incumple con el pago de las rentas aceptadas voluntariamente, inicia la omisión de lo prometido, destruye lo arrendado o no devuelve el predio en el tiempo convenido, empieza el problema de demandan gastos y pérdidas de dinero. Para evitar esos efectos no deseados, por seguridad propia y por costumbre se entrega un aval o garantía de esta manera se respalda el cumplimiento o resarcirnos del daño.

Por consiguiente, las garantías son medios que se utilizan para asegurar el cumplimiento de las obligaciones que asume, en este caso, el arrendatario. La función es la de disminuir la distancia entre la probabilidad y la certeza del cobro, y el cumplimiento las obligaciones, coloca al acreedor en una situación ventajosa al acortar el riesgo del arrendador.

A su vez, existen garantías de variadas características, pueden recaer sobre bienes inmuebles, muebles y semovientes (animales) del arrendatario o de un tercero. Hay garantías reales (hipoteca, prenda) y personales (fianza, aval, caución) (Vergara, 2016)

Así mismo, estos modos de asegurarse, pueden ser accesorios al contrato de arrendamiento o independientes a él.

\section{La realidad en Ecuador}

La falta de normativa de la institución jurídica de la garantía de arrendamiento de bienes inmuebles destinados a la vivienda causa un gran vacío legal en la legislación ecuatoriana, por estas razones en esta investigación se plantea la forma que debe incluirse la garantía en materia de Inquilinato como normativa y no solo como una cláusula creada por la costumbre que se incluye en los Contratos de Inquilinato.

Para que se declare cual debe ser la garantía a petición de parte, es requisito indispensable el que la omisión pueda influir en la decisión de la causa, como lo señala el Código Orgánico General de Procesos (COGEP), así si las partes ejercieron sus derechos, principalmente del lado más pequeño y débil que es el Inquilino. (Asamblea Nacional, 2015). 
La Ley de Inquilinato desde su iniciación hasta en la actualidad, ha llevado por fin esencial, la protección de los inquilinos, ya sea para evitar hasta donde sea posible, los abusos que podrían cometer los propietarios de viviendas como también, para evitar que se causen perjuicios materiales en los inmuebles en donde están las viviendas.

Cabe destacar, la obligación de firmar contrato escrito entre el arrendador y el arrendatario se considera como derecho de los arrendatarios, por otro lado, esta ley impone sanciones al arrendante por falta de ese documento lo que se debe entender que la carga es para el arrendante.

A su vez, lo indefinido del plazo del arriendo es otro de los beneficios que da el contrato escrito al inquilino ya que, si se ha fijado alguno, se entiende que al concluir no por eso termina el contrato de arriendo, sino que continúa en forma indefinida, siempre que se cumplan las otras condiciones que determina la Ley.

En forma aparente se ha favorecido al inquilino al no permitir al propietario que pueda aumentar el precio del arriendo, pero ello ha traído como consecuencia que no se construya más viviendas y la conservación de las existentes se vuelve cada día más difícil.

Los propietarios de inmuebles no quieren hacer ni siquiera las mejoras locativas, con el fin de que los antiguos inquilinos les desocupen sus bienes y así poder aumentar el precio del arriendo. No se crea que este problema sea solo salvadoreño. Se ha presentado más o menos con los mismos caracteres en distintos países. (Asamblea Nacional, 2013)

Por esta razón, se presentan obligaciones que debe cumplir el arrendador como el arrendatario. En este sentido, el arrendador debe entregar al arrendatario el inmueble arrendado, a su vez debe mantener el inmueble en estado de servir para el fin a que ha sido arrendada. Y debe librar al arrendatario de toda turbación en el goce del inmueble arrendada.

Por otro lado, el arrendatario debe gozar del inmueble según los términos del contrato, velar por la conservación del inmueble arrendado, pagar el precio o renta convenida. $Y$ restituir el inmueble a la terminación del contrato.

\section{Derecho a la vivienda}

El Derecho universal a una vivienda, digna y adecuada, como uno de los derechos humanos, aparece recogido en la Declaración Universal de los Derechos Humanos en su artículo 25, apartado 1 y en el artículo 11 de Pacto Internacional de Derechos Económicos, Sociales y Culturales (PIDESC): (Naciones Unidas de los Derechos Humanos, 1976). 
El derecho a una vivienda digna y adecuada, implica que la vivienda se ubique en espacios suficientemente equipados 0 , en el caso del medio rural, con accesibilidad suficiente, servicios y dotaciones en la zona. Así mismo, para que una vivienda sea digna y adecuada debe tener las siguientes características: que sea fija y habitable, de calidad, asequible -tanto en el precio de la vivienda como en alquiler-, accesible y con seguridad jurídica de tenencia.

\section{Seguridad jurídica}

\section{Legislación Ecuatoriana}

Es importante resaltar que el derecho constitucional a la seguridad jurídica se encuentra establecido en el artículo 82 de la Constitución, y señala que: "el derecho a la seguridad jurídica se fundamenta en el respeto a la Constitución y en la existencia de normas jurídicas previas, claras, públicas y aplicadas por las autoridades competentes". (Asamblea Constituyente, 2008)

De esta forma, la seguridad jurídica garantiza la confianza que los ciudadanos pueden tener en la observancia y el respeto de las situaciones derivadas de la aplicación de normas válidas y vigentes, además es el elemento esencial y patrimonio del Estado que garantiza la sujeción de todos los poderes públicos a la Constitución

En efecto, la legitimidad es la mayor aspiración de un Estado democrático que pretende que los ciudadanos acepten voluntariamente y por convicción el orden político y jurídico. Dicha aceptación voluntaria sólo puede darse si el ordenamiento jurídico se basa en principios dignos de ser reconocidos y que expresen un interés

\section{MÉTODO}

La investigación se basó en una investigación descriptiva, con un diseño no experimental, de campo, bajo la modalidad proyecto factible. En este estudio se usaron métodos como; el inductivo, deductivo, histórico-lógico, y analítico.

Inductivo, permitió establecer proposiciones de carácter general obtenidas de la observación que consistió en el registro de todos los hechos y su respectiva clasificación para obtener como resultado una conclusión de todos los hechos observados.

Deductivo, se obtuvo la información más amplia, ya que este método parte de lo general a lo particular.

Histórico-lógico, aclaró las distintas etapas de los objetos en sucesión cronológica, en las formas concretas de manifestación histórica. 
Analítico, las características a través de las partes que lo integran con el fin de identificar tanto su fuerza particular como las relaciones de correspondencia que guardan entre sí y dan origen a las características generales que se quieren conocer.

Por otro lado, la población que fue tomada en cuenta para esta investigación se ubicó en la zona centro de Ecuador, debido que es el lugar donde existen mayor cantidad de Inquilinos, lo cual constituye el enfoque de la investigación respecto de la garantía de arrendamiento. Como referente poblacional se ubicó en la Provincia de Pichincha, específicamente en el Distrito Metropolitano San Francisco de Quito, quedando la muestra constituida en 155 personas, distribuida de la siguiente manera; 90 inquilinos, 40 usuarios, y 25 representantes legales.

Seguidamente, la investigación usó como técnica, la observación, encuesta, y entrevista. Los instrumentos guía de registro de obsenvación y el cuestionario. Para el análisis de la información se utilizó como técnica el enfoque cualitativo, el cual permitió la clasificación y obtención de datos elaborados por letrados, consultores y especialistas en temas de propiedad intelectual. Los datos recolectados se procesaron de la siguiente manera:

- Clasificación: Los datos se ordenaron en base a parámetro de género, especie, cualitativos y cuantitativos.

- Tabulación: La información recolectada se organizó cuantitativamente a fin de que sirva como un mejor sustento a la investigación.

- Análisis: Una vez que fue organizada la información se procedió a analizarse a fin de encontrar los aspectos conducentes al cumplimiento del objetivo.

- Síntesis: La información obtenida se sustentará en argumentos que cumplan con los objetivos de la investigación dando una solución al problema

\section{RESULTADO Y DISCUSIÓN}

Para cumplimiento al objetivo principal de este estudio encuesta dirigida a los arrendadores, arrendatarios, representantes legales y ciudadanos que residen en el Distrito Metropolitano de Quito, arrojo los siguientes resultados:

En base a los datos recopilados se debe dar a conocer más la institución jurídica de la garantía de arrendamiento en materia de inquilinato, asimismo la mayoría de encuestados desconocen cuando se habla de una institución jurídica de la garantía de arrendamiento en materia de inquilinato, pero sí reconocen que existe una fuerte 
costumbre y que los arrendatarios la hacen obligatorias al arrendar un bien inmueble destinado a la vivienda.

Además, se debe dar a conocer más la garantía de arrendamiento en materia de inquilinato; ya que el $76,67 \%$ de los encuestados manifestaron que no conocen cual es el valor a pagar por concepto de garantía de arrendamiento. y añaden que este rubro se cobra de acuerdo a la voluntad de cada arrendatario o dueño de casa, que se cancela el mismo por costumbre y necesidad, antes de arrendar un bien inmueble destinado a la vivienda

Seguidamente, se señaló que la costumbre ha sido rector primario para el cobro de la garantía de arrendamiento, por esta razón, se debe difundir y socializar de mejor manera a la institución jurídica de la garantía de arrendamiento en materia de inquilinato, para precautelar los derechos ciudadanos.

También, se debe socializar con los ciudadanos sobre esta institución jurídica que no se encuentra normada en la legislación de Ecuador, ya que se determinó que los arrendadores, arrendatarios, representantes legales y ciudadanos que residen en el Distrito Metropolitano de Quito, desconocen la realidad social sobre la cual se basa la costumbre del cobro de garantía de arrendamiento.

En base a los datos recopilados se pudo determinar que en la actualidad no existe información sobre la garantía de arrendamiento en materia de inquilinato en las entidades de los municipales, básicamente, lo cual se debe a la falta de difusión y socialización de la garantía de arrendamiento en materia de inquilinato, en este contexto cabe resaltar que los municipios no informan sobre esta institución jurídica, porque no se encuentra normada.

Además, se determinó que la mayoría de los encuestados no conocen de una manera prolija, clara y oportuna todo el andamiaje que gira a través de la garantía de arrendamiento de bienes inmuebles destinados a la vivienda.

Por consiguiente, en la actualidad se cobra por costumbre un valor indeterminado por la garantía de arrendamiento, y suele ser el pago de dos meses por adelantado, es decir, el doble del canon de arrendamiento establecido por la voluntad de las partes.

La ciudadanía considera que es indispensable que se norme y socialice la figura de garantía de arrendamiento de bienes inmuebles destinados a la vivienda, para así poder mejorar y fortalecer la cultura ciudadana.

De esta manera, se considera importante para los arrendadores, arrendatarios, representantes legales y ciudadanos, conocer el monto a pagar por concepto de garantía de arrendamiento en materia de inquilinato, así se puede generar confianza y seguridad en este sector de la economía social. 


\section{Propuesta}

Partiendo del objeto de estudio de esta investigación, el cual está centrado en el desconocimiento sobre la falta de normativa y seguridad jurídica, es decir, de la garantía en materia de inquilinato, consecuentemente de la ciudadanía en general, hay que destacar que este hecho afecta directamente a los arrendadores y arrendatarios, principalmente sus derechos consagrados en la Constitución de la República, como el de uso y habitación, así también su estabilidad económica y social.

En este contexto, es sumamente importante que los arrendadores, inquilinos y ciudadanos en general, empiecen a tener conocimiento respecto de la garantía de arrendamiento, toda vez que es imperativo y necesario normar esta institución jurídica que, en la actualidad en el Distrito Metropolitano de Quito, se ha basado en la costumbre.

En virtud de lo expuesto se requiere establecer unas Políticas Públicas basadas a la socialización, información, difusión, por los diferentes medios de comunicación a fin de que tanto, el inquilino, como el dueño de casa o arrendador; conozcan sus obligaciones y derechos que emanan de la institución jurídica de la garantía.

De esta manera con el estudio realizado se busca socializar la garantía de arrendamiento en materia de inquilinato, a través de un Instructivo que sirva para socializar esta institución jurídica y se deba realizar a través del Municipio del Distrito Metropolitano de Quito, y por este medio difundir a los arrendadores y arrendatarios, para que el fin sea el bienestar del ciudadano y esté pueda establecer los derechos y obligaciones, de la regulación de la garantía de arrendamiento en materia de inquilinato.

\section{Descripción de la propuesta}

Se elabora un instructivo informativo a través del cual se va dar a conocer cuál es la institución jurídica de la garantía que es de vital importancia en la materia social de Inquilinato, con este propósito se busca que los inquilinos y arrendadores puedan conocer, de una forma clara y precisa ¿Cuánto se debe?; ¿Cómo se debe? y ¿Cuál es el monto máximo y mínimo que se debe pagar de garantía al momento de alquilar un bien inmueble?

En este contexto lo que se busca es socializar a través de los medios de comunicación, la prensa, redes sociales, conferencias, charlas etc., a usuarios, inquilinos y arrendadores del Distrito Metropolitano de Quito, la institución jurídica de la garantía en materia de Inquilinato, el cual deberá contener su monto máximo y mínimo. 
Instructivo del Proceso "La Institución de la Garantía en Materia de Inquilinato"

Este Instructivo, que aún no existe y que se considera importante para los inquilinos y arrendadores, será socializado a través del Municipio del Distrito Metropolitano de Quito.

Así también los Gobiernos Autónomos Descentralizados (Municipio y Prefectura), podrán difundir este instructivo, y será remitida a todas las administraciones zonales para su cabal cumplimiento, quienes se encargarán de socializar a sus contribuyentes, clientes y ciudadanos, después de esto remitirán un informe periódico de esta instrumentación a los Municipios (GAD'S).

Contenido del Instructivo del Proceso "La Institución de la Garantía en Materia de Inquilinato"

- La garantía en materia de Inquilinato.

- Rango de aplicabilidad respecto del monto de fijación de la garantía.

- Entidades inmersas en la defensa de los Derechos de arrendador y

- arrendatario.

- Obligaciones del arrendador y arrendatario.

- Derechos del arrendador y arrendatario.

CONCLUSIONES

La realidad social de Ecuador, principalmente en Quito ha generado un conflicto social, y de gran controversia como lo es la garantía de arrendamiento en materia de inquilinato, esta casuística se ha venido desarrollando durante varios años, la problemática que ha existido se radica principalmente en que no existe un rango de moderación para establecer la fijación de la garantía de arrendamiento de bienes inmuebles en materia de inquilinato. Esta realidad se ve reflejada en el diario cotidiano de los ciudadanos quiteños, razón por la cual esta investigación se basó en las experiencias y en el análisis sistemático, metodológico, y social.

La investigación trato aspectos fundamentales en materia de inquilinato ya que tanto el arrendador como el arrendatario, desconocen el tratamiento lógico de esta institución jurídica, es decir, el arrendador no sabe cuánto debe cobrar de garantía de arrendamiento de bienes inmuebles destinados a la vivienda y el arrendatario desconoce el rango de fijación de este valor. En este contexto se concluye que es de vital importancia, normar y socializar la garantía de arrendamiento de bienes inmuebles destinados a la vivienda. 


\section{REFERENCIAS}

Asamblea Constituyente . (2008). Constitución de la República del Ecuador. Montecristi, Ecuador, Manabí

Asamblea Nacional. (2013). Ley de Inquilinato. Registro oficial 196 I-XI-200. Quito, Ecuador: Ediciones Legales

Asamblea Nacional. (22 de Mayo de 2015). Código Orgánico de la Función Judicial. (Registro Oficial Suplemento 544 de 09mar.-2009. Última modificación: 22-may.2015.). Quito, Ecuador

Código Federal de Procedimientos Civiles. (09 de Abril de 2012). Nuevo Código publicado en el Diario Oficial de la Federación el 24 de febrero de 1943. Última actualización 2012. Chile
González, J. (2000). Derechos del Arrendador. México: UNAM

Naciones Unidas Derechos Humanos. (3 de Enero de 1976). Pacto Internacional de Derechos Económicos, Sociales y Culturales. Adoptado y abierto a la firma, ratificación y adhesión por la Asamblea General en su resolución $2200 \mathrm{~A}(\mathrm{XXI})$, de 16 de diciembre de 1966

Santa María, J. (1998). Los Contratos Parte General. Santiago de Chile, Chile: Jurídica de Chile

Vergara, S. (2016). Hipoteca. P 83 s/E. Colombia 